\title{
HISTORICAL FORENSIC PATHOLOGY
}

\author{
Roger Byard ${ }^{1}$
}

${ }^{1}$ University of Adelaide, Adelaide, Australia

Correspondence: roger.byard@sa.gov.au

\section{Introduction}

Pathology is traditionally regarded as the study of injury and disease, and forensic pathology refers to those aspects of the discipline which apply to the law. Thus, forensic pathologists over the world undertake much of the same types of activities, performing autopsies for legal authorities, attending crime scenes with law enforcement officers, compiling reports and preparing material for the evaluation in court $(1,2)$. Additional activities include teaching university students and trainee pathologists, as well as undertaking research. The latter activity is fascinating, as the spectrum of research in forensic pathology is vast, ranging from simple case reports detailing unusual injuries or mechanisms of death, to much more elaborate laboratory-based genetic and animal studies.

Preventive Pathology

The results of forensic pathology research activities can have very direct effects on the community. For example, "Preventive Pathology" is a name coined to explain the results of injury monitoring in infants and young children that has been carried out in Adelaide for several decades $(3,4)$. This is based on the "Keeping your Baby and Child Safe Program" which simply refers to the process of recording and analysing all accidental deaths in the young that were presented for autopsy to the South Australian state forensic morgue. Potentially preventable deaths, sometimes associated with dangerous products or sleeping environments, are identified and evaluated, with formulation of recommendations for parents, community organizations and product safety groups within government (5). This very simple form of prospective research has been very successful in reducing deaths over the years from a number of dangerous situations.

\section{Historical Forensics}

Another area that has not been well developed is Historical Forensics. This refers to the use of modern forensic techniques and analyses to examine historical events or situations. The results of this are quite varied and may i) provide answers to historical questions, ii) expand our understanding of particular contemporary forensic issues, and iii) demonstrate a particularly interesting feature of a recorded event.

In an effort to promote this area of forensic pathology, a section of the journal Forensic Science Medicine and Pathology was initiated, entitled "Lessons from the Museum". This section deals with short reports that describe forensic cases from pathology museums. Professor Nikolić and Professor Živković from the University of Belgrade have been very active in this area and have contributed many cases derived from the museum collection at the University that was developed by Professor Milovan Milovanović (1884-1948). Topics have been quite fascinating and have ranged from infanticide to aortic dissection in Marfan syndrome (6-11). The following brief examples taken from an Australian context will be described to demonstrate the scope of Historical Forensics as a distinct sub-speciality of forensic pathology. 


\section{i) Answering historical questions}

Ben Hall was an outlaw (or "bushranger") in nineteenth century Australia who, with his gang, was responsible for innumerable robberies, which occasionally resulted in the death of serving police officers (12-14) (Figure 1). A substantial reward was placed on Hall's head and he was finally shot and killed by members of the New South Wales Constabulary on May 5 1865, near Billabong Creek, outside the town of Forbes. Controversy exists over his final moments with the police claiming in contemporary reports that he was shot by Sergeant Hipkiss with a 0.56 carbine through his gun belt, contrasting with popular legend that he was executed by police who fired multiple rounds into him while he was sleeping by a campfire.

The gun belt allegedly belonging to Ben Hall is located in the Museum of Applied Arts and Sciences in Sydney, New South Wales (Figure 2) and was made available for examination during the filming of "Lawless", a documentary on bushrangers produced in association with Genepool Productions and Foxtel (15). Despite its unremarkable appearance on display, once the broken ends had been mobilized and approximated, an oval defect was created that had an approximately back to front orientation with obvious shelving and undermining of the anterior margin (Figure 3). The defect would have been located over the left flank of the belt wearer and was quite consistent with the effects of a large caliber bullet fired from a position behind and to the left of the decedent where police stated that Sergeant Hipkiss had been standing. Scanning electron microscopy detected lead, as well as silver, sulphur and mercury, materials used as primers in nineteenth century ammunition. This contemporary examination utilizing modern investigative techniques therefore supports the police version of events (14).

Captain Moonlite (Figure 4) was another nineteenth century Australian bushranger who was involved in a shootout with police at Wantabagery Station in the colony of New South Wales on the November 16th 1879 (16). During the melee three gang members were killed by police and Sergeant Webb-Bowen was mortally wounded in the neck, dying of the injury a number of days later. Prior to this investigation no-one has been sure who could have fired the fatal shot. However, by combining an

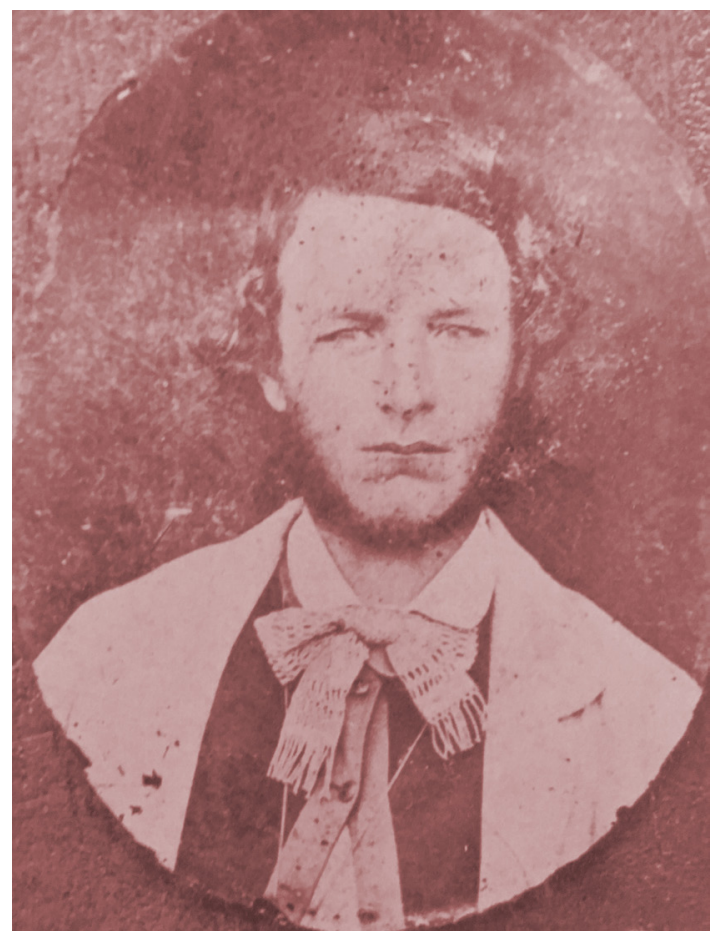

Figure 1. A photograph of Ben Hall (with permission of the Forbes Historical Society).

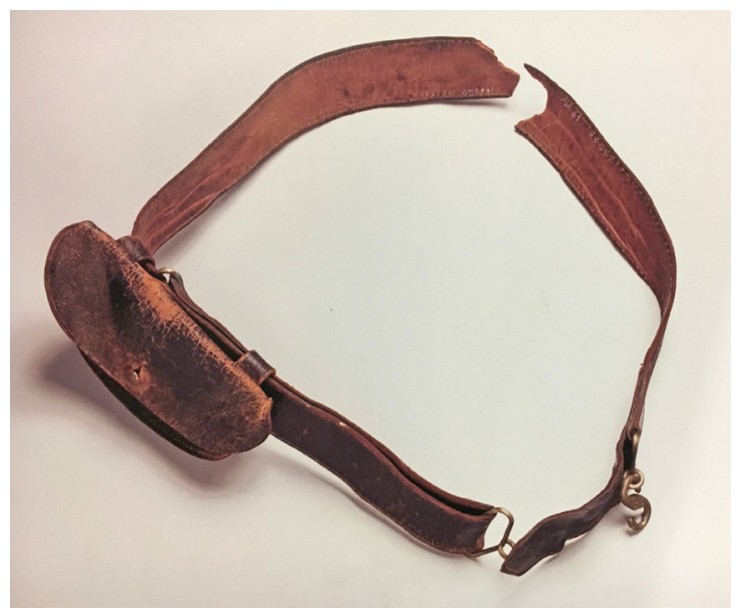

Figure 2. A nineteenth century gun belt at the Museum of Applied Arts and Sciences in Sydney, New South Wales that was allegedly worn by Ben Hall on the morning of his fatal shooting.
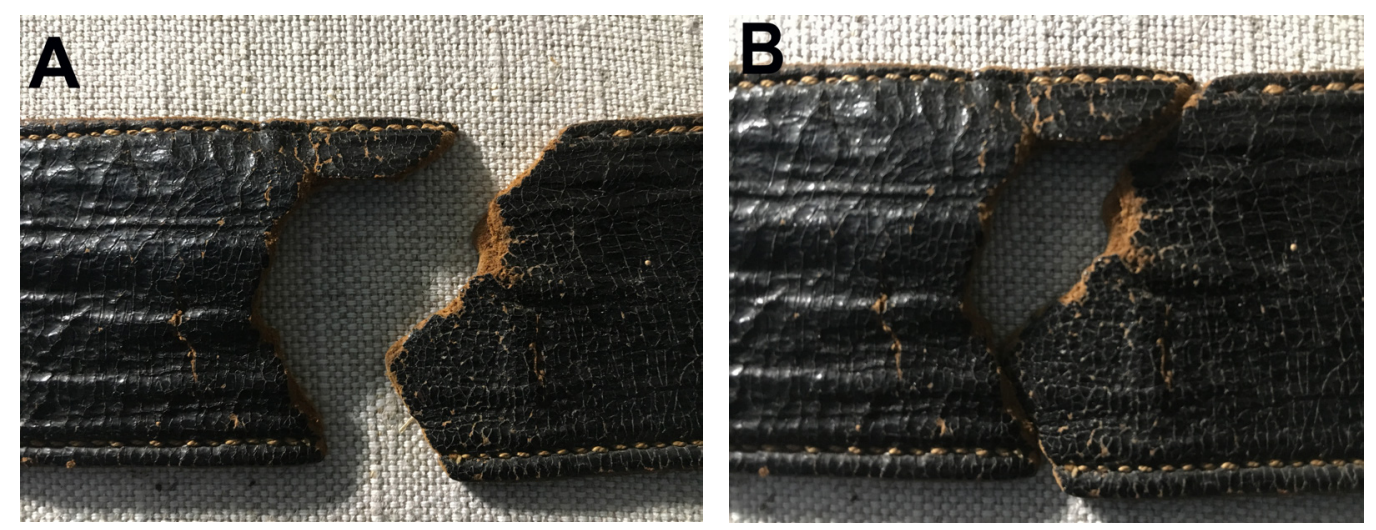

Figure 3. The defect in the gun belt as displayed in the museum (A). The appearance of the bullet hole once the two ends of the belt had been approximated (B). 
archeological assessment of the site with LIDAR scanning technology during the filming of another episode of "Lawless", the scene could be reconstructed at a special viewing facility at Monash University in Melbourne, Australia (16).

By removing vegetation and "rebuilding" the farm houses that existed at the time of the shoot-out, the reconstructed virtual "scene" could be populated with the protagonists (Figures 5 \& 6). Integrating details of the fatal wound from the police officer's autopsy report that was included in the court record with the LIDAR reconstruction indicated that, most likely, the shooter was the youngest gang member, Gus Warneke, who was also killed that day. Thus, the two bushrangers who were hung on the January 20th 1880 for the murder of Webb-Bowne were not the shooters, although as a gang leader, Moonlite did bear responsibility for the outcome that day. The question of who fired the fatal shot has been resolved (16).

ii) Expanding our understanding of contemporary forensic issues

The island of Tasmania, once known as Van Diemen's Land, lies off the south coast of mainland Australia in the cold waters of the Southern Ocean. It was settled in the early nineteenth century as a convict penitentiary and the records of all of the felons transported to Van Diemen's Land from England are kept today in the Tasmanian Archive and Heritage Office (TAHO) in 533 volumes (Figure 7) (17). There are details of approximately 73,000 convicts $(59,500$ men and 13,500 women) which provides information on the offences, transportation dates and punishments meted out. It is an incomparable resource on the UNESCO World Heritage Register (17).

Sarah Island on the windswept and desolate west coast of the island was the settlement used for the most incorrigible of the convicts. Although debated, it appears clear that the convicts at the time had evolved an unusual form of murder suicide with features slightly similar to modern day "death by cop" scenarios. Convicts would draw lots to see who would leave the island by being murdered, with the perpetrator also "escaping" through the inevitable judicial execution (18). The convicts referred to the island as "Devils" Island or "Pluto Land" after the

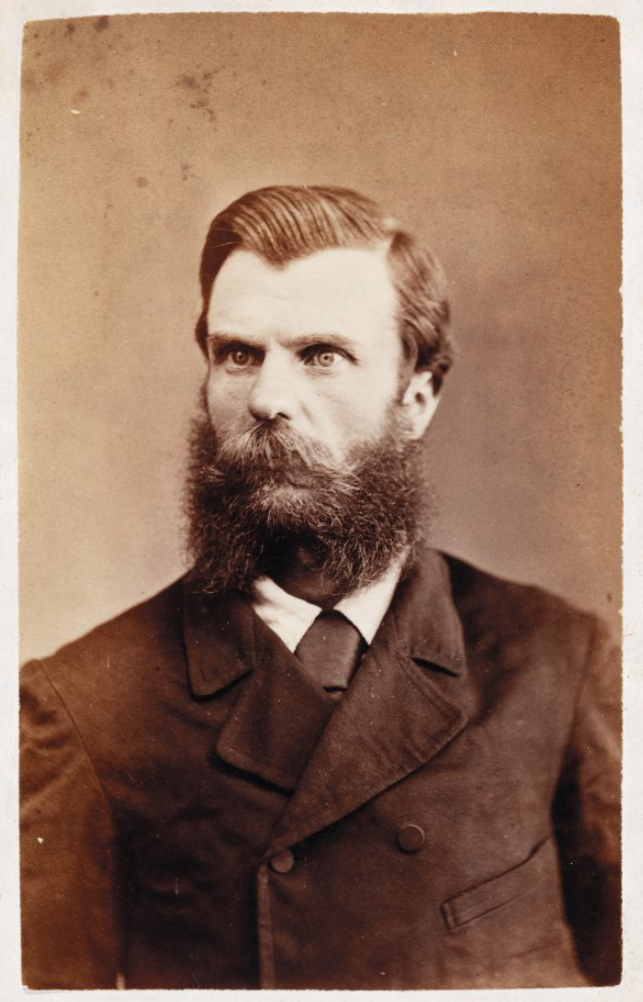

Figure 4. A contemporary photograph of Captain Moonlight a.k.a George Scott (Reproduced with permission from the collection of Victoria Police, Australia).

Roman God of the dead, as the conditions were so dreadful. The historian John West stated that the island was "sacred to the genius of torture" and that it was "impossible to give an idea of the hardships and misery" of this dreadful place. For example, in one week alone, 15 convicts received 1700 lashes (18).

Records detailed an incident in October 1827, where nine convicts captured six jailers and then tried to escape on a raft which sank, unfortunately for them. The fallback position was to murder one of the convict overseers in front of his bound and gagged colleagues, who were left alive as witnesses to the event. The purpose of these actions was to be taken back to Hobart Town for execution, to escape the horrors of Devils Island forever. Analysis of this event expands our classification of murder suicide by demonstrating another subcategory that could be termed "judicial murder suicide" where legal processes and consequences were used to ensure death (and therefore

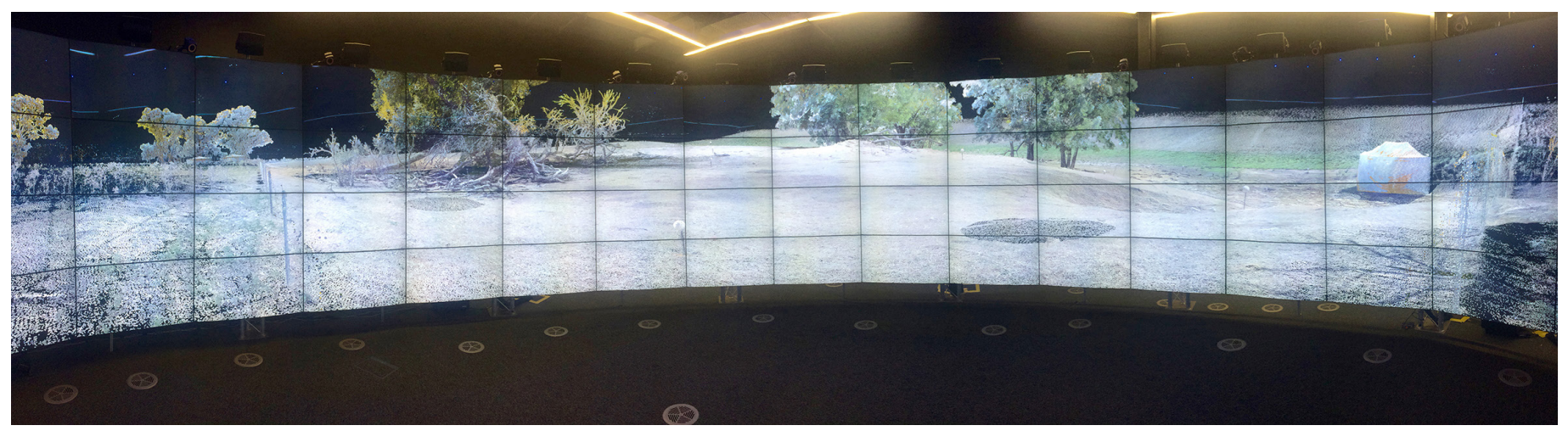

Figure 5. Recreation of the location of the siege using a LiDAR-derived digital terrain model at the Monash University 'CAVE2' facility, Melbourne, Australia. 


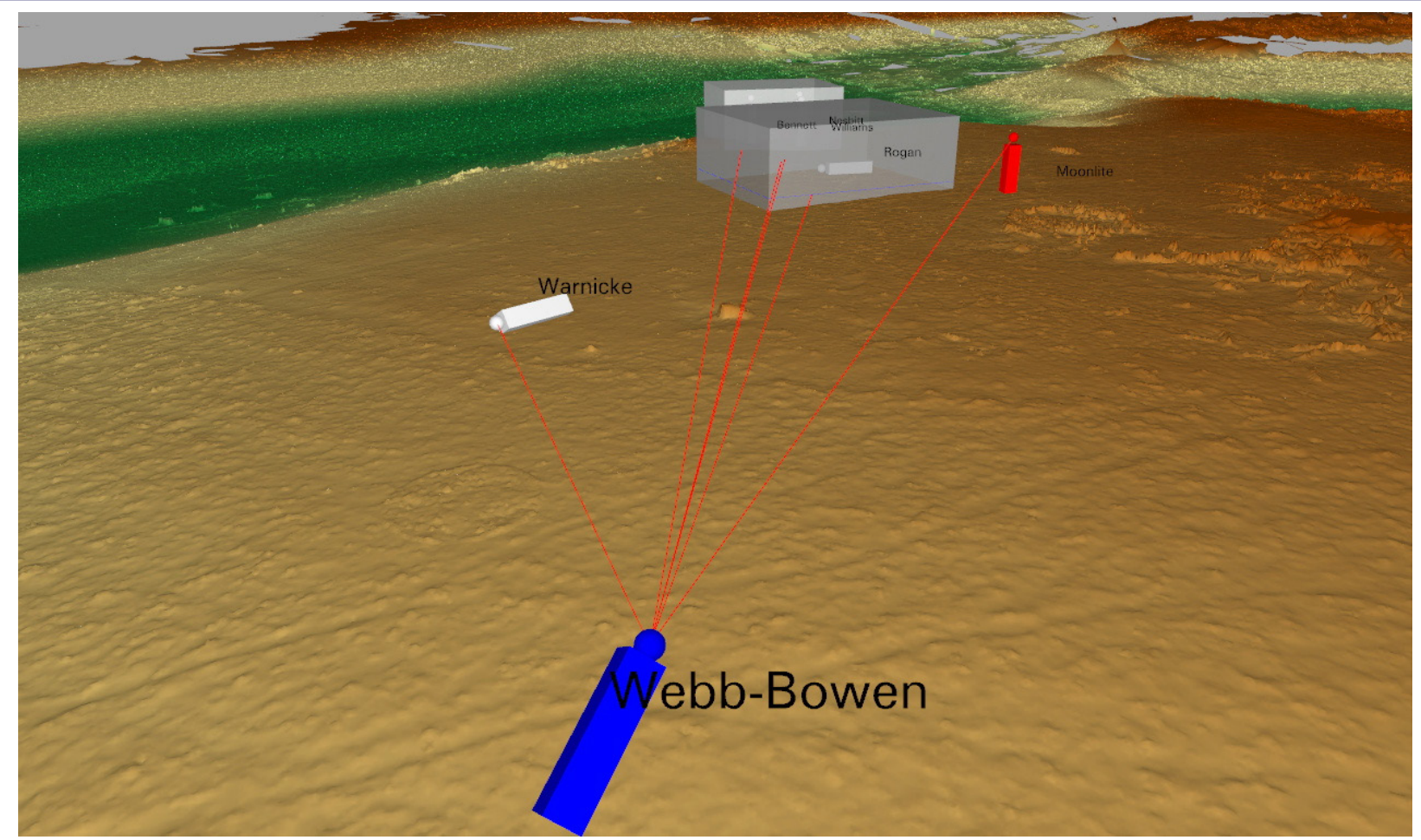

Figure 6. A near ground level view using the LiDAR-derived digital terrain model at the Monash University 'CAVE2' facility with vegetation removed and insertion of buildings and protagonists into the Wantabadgery siege location showing potential lines of fire.

"escape") of the perpetrators (18). On occasion escaping convicts, such as the notorious Alexander Pearce, had resorted to cannibalism on more than one occasion (Figure 8) (19).

iii) Demonstrating a particularly interesting feature of a recorded event

Included in the pathology archive at The University of Adelaide are a series of documents and graphs detailing deaths and illnesses from infectious diseases amongst men who were enlisted as members of the Egyptian Expeditionary Force in the Middle East during World War I (WWI) (Figure 9). The material shows the damage to fighting forces from infectious diseases compared to enemy fire, such that the number incapacitated by infections was an extraordinary 37 times that of soldiers injured or killed by bullets or shrapnel (20).

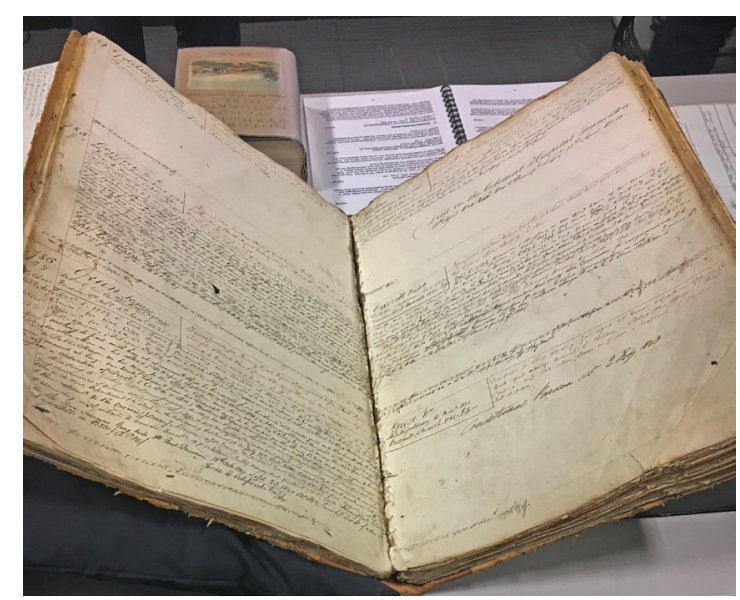

Figure 7. An archive volume located at the State Library of Tasmania (Tasmanian Archive and Heritage Office, TAHO).

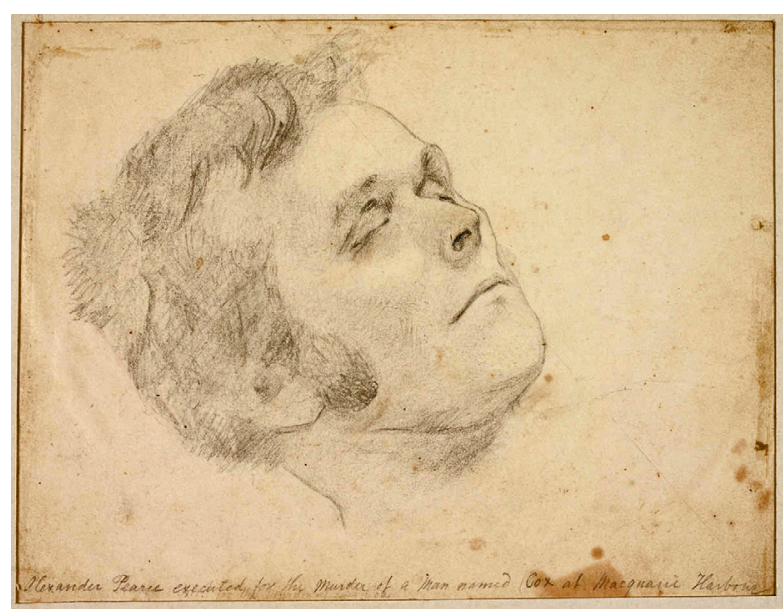

Figure 8. A sketch by the convict artist Thomas Bock of the head of Alexander Pearce after his execution. The caption reads 'Alexander Pearce executed for the murder of a man named Cox at Macquarie Harbour' (State Library of New South Wales).

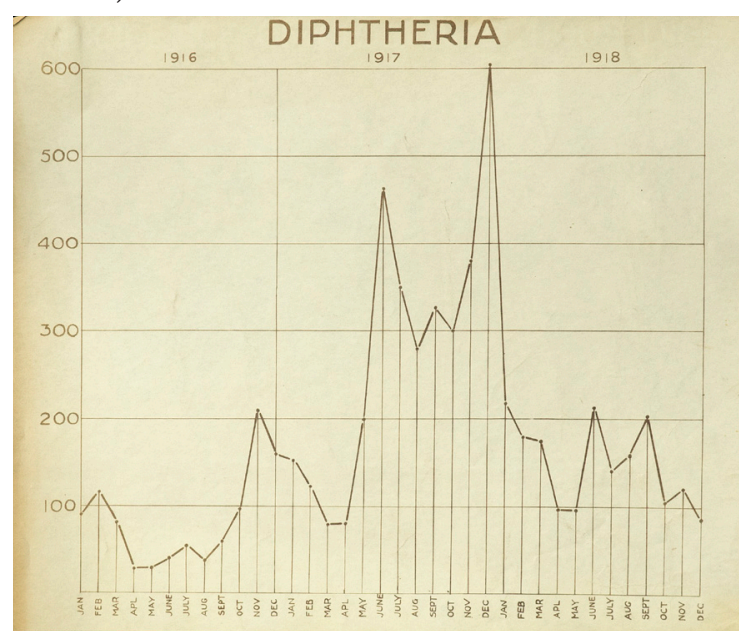

Figure 9. Cases of diphtheria between 1916 and 1918 in soldiers of the Egyptian Expeditionary Force with two peaks - June and December 1917. A total of 3342 hospital admissions for diphtheria were recorded for that year. 


\section{Conclusion}

These brief reports clearly show that contemporary forensic examination and analyses of material and specimens currently residing in museums may clarify historical questions that have been unanswered for many decades. Review of data may also provide graphic illustration of significant conditions and illnesses that are sometimes overlooked in the face of the far more dramatic aspects of armed conflict. Although administrators often fail to see the relevance of pathology museums, being more interested in dealing with costs than contributing to knowledge, historical forensic pathology has a distinct and important role to play in the contemporary multidisciplinary analysis of past events.

\section{References}

1. Prahlow J, Byard RW. An Atlas of Forensic Pathology, New York, Springer Publishers, 2012.

2. Payne-James J, Byard RW. Encyclopedia of Forensic and Legal Medicine. Volumes 1- 4. 2nd Edition, Oxford, Academic Press, 2016.

3. Byard RW. Preventative pathology. Inj Prevent 1999;5:292-3.

4. Byard RW. Preventive pathology revisited. Forensic Sci Med Pathol 2014;10:155-6.

5. Byard RW. Accidental childhood death and the role of the pathologist. Pediatr Develop Pathol 2000;3:405-18.

6. Nikolíc S, Živković V. A healed bony puzzle: an old gunshot wound to the head. Forensic Sci Med Pathol 2013;9:112-6.

7. Nikolíc S, Živković V. Attempted suicide with an axe: a hanged waiter with multiple healed chop wounds to the crown of the head. Forensic Sci Med Pathol 2013;9:117-21.

8. Nikolíc S, Živković V. Infanticide from intentional choking: the use of evaluating older cases. Forensic
Sci Med Pathol 2013;9:596-601.

9. Nikolíc S, Živković V. a train-related fatality - old dilemmas: accident suicide, or homicide? Premortem or postmortem decapitation? Forensic Sci Med Pathol 2014;10:278-83.

10. Nikolíc S, Živković V. Two cases of homicidal corrosive poisoning: once upon a time. Forensic Sci Med Pathol 2015;11:136-41.

11. Nikolíc S, Glumac S, Živković V. Aortic dissection in a young adolescent: never too late to solve a case. Forensic Sci Med Pathol 2015;11:303-6.

12. White C. History of Australian Bushranging. Vol 1. Hawthorn; Lloyd O’Neil Pty Ltd, 1970.

13. Bradley P. The Judas Covenant. The Betrayal and Death of Ben Hall. 2nd ed. Sydney; Yellow Box Books, 2013, p 119.

14. Byard RW, McDonald D. The death of Ben Hall. Forensic Sci Med Pathol 2018;14:268-71.

15. https://www.historychannel.com.au/shows/lawless-the-real-bushrangers/ (accessed 20 July 2018).

16. Byard RW, Ford A, Raymond T, Sofonia JJ, Kaluza $\mathrm{O}$, Barnes DG. Line of fire - what happened at the Wantabagery siege? Forensic Sci Med Pathol 2018;14:133-6.

17. Byard RW, Maxwell-Stewart H. The potential forensic significance of convict archives from Van Diemen's Land, 1820-1877. Forensic Sci Med Pathol 2018;14:127-32.

18. Byard RW, Maxwell-Stewart H. Judicial murder-suicides in Van Diemen's Land. J Forensic Sci (In press).

19. Byard RW, Maxwell-Stewart H. Cannibalism amongst penitentiary escapees from Sarah Island in nineteenth century Van Diemen's Land. Forensic Sci Med Pathol (In press).

20. Byard RW. Morbidity and mortality from infectious disease in the Egyptian Expeditionary Force (19161918). Forensic Sci Med Pathol 2018;14:263-7. 